\title{
A PARTICIPAÇÃO DE FEMINISTAS NA BUROCRACIA ESTATAL: DINÂMICAS E EFEITOS 12
}

\author{
Milena Cristina Belançon ${ }^{3}$
}

\begin{abstract}
RESUMO
O "ativismo estatal" (ou "institucional"), caracterizado pela atuação de militantes de movimentos sociais na burocracia estatal, foi adotado por parcelas de movimentos feministas no Brasil, principalmente a partir da redemocratização do país, momento em que as mulheres passaram a buscar vias de luta por direitos para além das instâncias tradicionais de representação e dos repertórios característicos da ação direta. Neste trabalho buscou-se contextualizar a trajetória do movimento feminista que adentrou o Estado e suas dinâmicas, uma vez inserido na burocracia institucional. $\mathrm{O}$ foco do trabalho está em compreender a execução desse repertório de ações e suas implicações para os movimentos em si e para o Estado, a partir da exploração de distintas trajetórias de mulheres que atuaram em cargos públicos não eletivos.
\end{abstract}

Palavras-chave: Feminismo. Ativismo. Estado.

\begin{abstract}
The "State activism" (or institutional), characterized by the action of militants of social movements in the state bureaucracy, was adopted by plots of feminist movements in Brazil, mainly from redemocratization, the moment when women began to seek struggles for rights beyond the traditional instances of voting and characteristic list of direct action. In this work, we seek to contextualize a trajectory of the feminist movement that entered the State and its dynamics once inserted in the institutional bureaucracy. The focus of the work was to understand the implementation of this repertoire of actions and approached their gains, as well as the limits and impacts it generates in the State and in the movements themselves, based on the exploration of distinct trajectories of women who worked in non-elective public positions (the state feminist).
\end{abstract}

Keywords: Feminism. Activism. State.

\section{RESUMEN}

El "activismo estatal" (o "institucional"), caracterizado por la actuación de militantes de movimientos sociales en la burocracia estatal, fuera adoptado por pequeños grupos de movimientos feministas en Brasil, principalmente desde la redemocratización del país, momento en que las mujeres pasaron a buscar vías de lucha por derechos más allá de las instancias tradicionales de representación y de los repertorios característicos de la acción directa. En este trabajo se buscó contextualizar la trayectoria del movimiento feminista que adentró el Estado y sus dinámicas, una vez insertado en la burocracia institucional. El objetivo del trabajo está en comprender la ejecución de ese repertorio de acciones y sus implicaciones para los movimientos en sí y para el Estado, se basa en el estudio de distintas trayectorias de mujeres que actuaron en cargos públicos no electivos.

Palabras clave: Feminismo. Activismo. Estado.

\section{INTRODUÇÃO}

As mudanças ocorridas a partir da redemocratização brasileira ampliaram o leque de ações coletivas no Brasil, abrindo novas oportunidades de participação política para os movimentos sociais. Nesse contexto, tornaram-se alvo de forte atenção da bibliografia as instâncias de participação institucionalizada que, a exemplo dos conselhos gestores, passaram

\footnotetext{
${ }^{1}$ Enviado: 31/10/2017. Aceito: 10/11/2017.

${ }^{2}$ DOI: http://dx.doi.org/10.5380/recp.v9i1.56129

${ }^{3}$ Mestranda em Ciências Sociais pela Universidade Estadual de Maringá. Bacharela e licenciada em Ciências Sociais pela mesma universidade. Pesquisadora do Núcleo de Pesquisas em Participação Política (NUPPOL/UEM). E-mail: milenabelancon@gmail.com
} 
a incluir organizações da sociedade civil e movimentos sociais nos processos decisórios de políticas públicas. Entretanto, mais recentemente, estudos passaram a chamar a atenção para um repertório até aqui pouco abordado, que diz respeito à ocupação de cargos públicos não eletivos por ativistas de movimentos sociais que buscam, por esse caminho, intervir diretamente na produção das políticas públicas.

$\mathrm{Na}$ América Latina, esse repertório ganhou notoriedade com a chegada, nos governos de vários países, de partidos políticos de esquerda, como foi o caso do Partido dos Trabalhadores (PT) no Brasil. Tal chegada causou uma maior proximidade entre Estado e movimentos sociais, o que resultou na experimentação criativa de novos padrões de interação entre ambos (ABERS; SERAFIM; TATAGIBA, 2014).

O "ativismo institucional" ou "ativismo estatal", como é nomeado pela bibliografia, diz respeito, assim, aos "participantes de movimentos sociais que ocupam status formais dentro do governo, que perseguem objetivos do movimento através dos canais burocráticos, que têm rotina como membros políticos" (CAYRES, 2015, p. 61). Com base nesse repertório, alguns estudos têm proposto, inclusive, um novo conceito de movimentos sociais que reconheça os ativistas inseridos na burocracia estatal como seus integrantes (CAYRES, 2015; ABERS; BULLOW, 2011).

Neste trabalho nós pretendemos analisar alguns dos desafios e dos limites constitutivos do ativismo institucional a partir da consideração das feministas, tendo como referência o caso brasileiro e as trajetórias de duas mulheres que ocuparam cargos na burocracia estatal e que, devido às diferenças entre si, nos parecem particularmente propícias para o exame e a exploração de algumas das expectativas teóricas e empíricas que cercam esse tipo de repertório. Como veremos, as trajetórias investigadas expressam meios inversos e diferenciados de ingresso na burocracia estatal, os quais impactam a forma como essas ativistas atuam e se enxergam como feministas no interior do Estado.

Cumpre notar ainda nessas notas introdutórias que a exploração do repertório do ativismo institucional para o movimento feminista é particularmente importante na medida em que as mulheres enfrentam fortes barreiras para atingir cargos públicos eletivos. Assim, podemos supor que, para esse movimento, dada a histórica sub-representação de mulheres na política, o ativismo estatal, ou seja, a ocupação de cargos públicos não eletivos por participantes de movimentos sociais, pode ser uma alternativa às eleições como caminho para aumentar a representatividade das mulheres nas tomadas de decisão e efetivar demandas feministas. 
Para tanto, primeiramente, retomamos a bibliografia que trata do tema para situar o contexto em que o ativismo institucional abriu-se como horizonte para as feministas brasileiras. $\mathrm{Na}$ segunda parte do artigo, analisamos as informações a respeito das duas trajetórias consideradas, as quais foram coletadas a partir de entrevistas semiestruturadas realizadas com feministas institucionais ${ }^{4}$. Finalizamos com uma breve conclusão, destacando alguns achados que as trajetórias analisadas apresentaram para o exame das expectativas que cercam o ativismo estatal.

\section{CAMINHOS DO MOVIMENTO FEMINISTA BRASILEIRO}

Para entender como o ativismo institucional colocou-se na perspectiva das feministas, é preciso contextualizar as ondas do movimento feminista brasileiro. Por mais que haja muitos debates acerca da adequação da noção de "ondas" para tratar dos feminismos do sul global, já que ela foi formulada em referência aos feminismos europeu e norte-americano, faremos uso desse instrumento a fim de analisar as relações e inflexões entre os movimentos feministas e o Estado no Brasil.

As primeiras manifestações de mulheres pela igualdade no Brasil acompanharam o que ocorria na Europa e nos Estados Unidos em relação ao tema da educação para emancipação - guardadas suas particularidades, tendo em vista a diferença entre os países capitalistas centrais e os periféricos. Nesse sentido, acompanhando as ondas do feminismo hegemônico, na década de 1920 lideranças feministas no Brasil clamaram pelo sufrágio, o que foi conquistado na década seguinte.

Outro período de grande destaque da luta do movimento de liberação feminina ocorreu durante as décadas de 1960 e 1970, quando as mulheres participaram também de organizações clandestinas de esquerda e de grupos guerrilheiros de combate à ditadura militar, instaurada em 1964 no Brasil.

É nesse período que despontam mais abertamente as mobilizações de mulheres e feministas por diferentes pautas. Eva Blay (2008) as classifica em dois grandes grupos: primeiro, o das reivindicações relativas à vida cotidiana, pautadas nas lutas contra a carestia, pela instalação de creches e pela promoção de bens urbanos; e, segundo, o das demandas pela cidadania, dizendo respeito às ações dentro dos partidos políticos e à estrutura do Estado.

\footnotetext{
${ }^{4}$ As duas entrevistadas assinaram um Termo de Consentimento Livre e Esclarecido, por meio do qual foram informadas dos objetivos da pesquisa. Para preservar a privacidade, não vamos identificá-las pelos seus nomes diretamente quando citarmos suas informações verbais.
} 
Assim, mesmo as reinvindicações referentes à vida cotidiana revelaram uma preocupação dos movimentos sociais com relação à questão de gênero, por serem lideradas por mulheres e abarcarem pautas do "cotidiano feminino", , rompendo a esfera privada e atingindo a esfera pública e, também, servindo como instrumento de emancipação.

Segundo Lúcia Avelar (2015), das atuações dessas mulheres nessas mobilizações, juntamente com uma maior participação delas na educação, no mundo do trabalho e nos movimentos estudantis, decorreram alguns eventos, como a criação de departamentos femininos dentro dos partidos e dos movimentos sociais e, também, o empoderamento de mulheres que se tornaram lideranças em seus bairros, comunidades, igrejas etc.

A participação nesses diferentes movimentos estendeu os horizontes das mulheres, fazendo-as aprender outras formas de fazer política, as quais extrapolavam os canais partidários e possibilitavam sua constituição como atrizes políticas relevantes no período democrático que se abria.

Com o fim da ditadura em meados da década de 1980, as mulheres já estavam exercendo ações profissionais em militâncias, principalmente em ONGs que visavam promover a igualdade de gênero. Assim, estavam dispostas a trilhar outros caminhos que não as instâncias tradicionais de acesso ao poder político, como formas de ativismo inovadoras e, também, reinventando a relação entre Estado e sociedade. Desse modo, os avanços nas pautas feministas foram acontecendo no pós-ditadura mesmo com a pequena presença feminina nas instâncias tradicionais de representação.

A representação extraparlamentar foi, portanto, uma alternativa encontrada em meio às dificuldades para que as pautas feministas chegassem à agenda pública. Essa representação extraparlamentar foi exercida também nos canais abertos em instâncias do Estado, como o Orçamento Participativo, os Conselhos Gestores, as conferências temáticas, as comissões e as secretarias. Com o advento da redemocratização, depois de muitas lutas dos movimentos sociais, há uma abertura para que a sociedade civil ocupe o Estado, por meio, por exemplo, das instituições participativas, implementadas legalmente através da Constituição de 1988 e melhor difundidas na década de 1990, tendo como sua principal inovação o caráter híbrido em sua composição, mesclando representantes do governo e da sociedade civil. Segundo Rangel, citada por Avelar,

As mulheres tiveram sucesso em transitar por distintos espaços e influenciar decisões nos três poderes... por meio do novo patamar institucional de intermediação

\footnotetext{
5 Tendo em vista a construção social que considera as práticas do cuidado quase que exclusivamente como responsabilidade das mulheres, discussão central dos feminismos.
} 
entre Estado e sociedade e de representação nas formas de participação... tornando mais claras as relações entre representação substantiva e descritiva das mulheres e o impacto dos movimentos feministas sobre as políticas. (RANGEL apud AVELAR, 2013, p. 73).

Cayres (2015) afirma que, com a consolidação dessas instituições participativas como parte do sistema político brasileiro, a agenda de pesquisa passa a questionar as visões polarizadas postas até então a respeito da relação Estado e movimentos sociais, buscando conhecer melhor as fronteiras entre a política "das ruas" e a política institucionalizada. Porém, a participação institucionalizada passou a ser alvo de críticas por parte de alguns que viam no contato com a máquina burocrática do Estado uma possibilidade de "contaminação" dos movimentos, ou seja, sua cooptação.

Em se tratando particularmente do campo feminista, Alvarez (2014) salienta que, por este ser um campo em constante luta política por hegemonia, há divergências entre as feministas "autônomas" e as feministas "institucionais". As primeiras são aquelas que negam qualquer tipo de institucionalização dos movimentos e as últimas são como aquelas das quais tratamos nesse texto, ou seja, as que enxergam a proximidade com o Estado como estratégica e buscam o avanço de pautas através dela. A autora afirma, ainda, que, para as autônomas, as feministas que se aliaram de alguma forma ao Estado traíram o movimento feminista, adentrando a burocracia do Estado.

Apesar das disputas internas do movimento feminista, podemos afirmar que a estratégia de ativismo por dentro do Estado é uma importante inserção das feministas na disputa pelos espaços de poder, sendo que elas, segundo Alvarez (2014), têm logrado importantes avanços na legislação e nas políticas públicas, aliada às outras formas de ativismo.

Portanto, essa é uma das formas possíveis de ativismo, o que não exclui formas de ação coletiva direta. Como analisa Mariano (2001), a manutenção dos movimentos exteriores ao Estado é fundamental, até mesmo no sentido de se exercer pressão nas instituições em consonância com o feminismo institucional.

Os avanços que contaram com o apoio do ativismo institucional feminista incluem desde a Lei Maria da Penha, que trata da criminalização da violência doméstica e do assédio sexual, até a criação de diversas instâncias de mediação específicas entre as organizações de mulheres/redes feministas e o Estado, como conselhos de mulheres, procuradorias das mulheres, bancadas nacionais, delegações, comissões de assessorias e comissões parlamentares.

\footnotetext{
${ }^{6}$ Termos usados por Alvarez (2014).
} 
Avelar (2013) se aprofunda no tema "feminismo de Estado" expondo as relações entre as redes feministas — sendo as principais delas a Articulação de Mulheres Brasileiras (AMB), a Marcha Mundial das Mulheres (MMM) e a União Brasileira de Mulheres (UBM) — e as agências estatais. Segundo a autora, a interação entre elas é vertical e horizontal, o que acaba por compartilhar e fortalecer suas temáticas principais com o fim de alcançarem visibilidade na agenda pública. Segundo Avelar,

Femocratas $^{7}$ são feministas que trabalham na burocracia do Estado, influenciando o processo político na formação da agenda pública com os temas de interesse das mulheres, incrementando o debate, enfatizando a sua importância para as mulheres e influenciando nas decisões da burocracia do Estado. (AVELAR, 2015, p. 216).

Como já foi dito, essa estratégia não foi adotada somente pelas mulheres. No contexto de redemocratização advindo do fim da ditadura, Feltran (2006, p. 373) afirma que essa foi uma aposta de diversos movimentos, que se ancoravam na "possibilidade de migração das demandas e anseios dos movimentos sociais para canais de participação ativa da sociedade civil na gestão e na definição do funcionamento do Estado". Busca-se então a democratização junto ao Estado, articulando-se o processo eleitoral com canais de acesso da sociedade civil às instâncias do governo, ideia esta baseada em uma forte promoção de justiça social. É o que mostra também Mariano (2001) ao tratar da incorporação das demandas feministas pelo Estado como um elemento ampliador da democracia.

Sobre o ativismo institucional de diversos movimentos e indivíduos, Cayres (2015) afirma que parte da bibliografia ainda não aprova que os movimentos sociais façam parte do Estado para alcançar seus objetivos, mas já há estudos que enxergam essa estratégia como parte constitutiva de tais movimentos. A autora parte de diversos exemplos que apontam para o ativismo institucional como uma estratégia de sucesso, o que é mostrado também por Avelar (2013), que cita exemplos no âmbito da saúde (como a Rede Nacional Feminista de Saúde do Ministério da Saúde e a Rede pela Humanização do Parto e Nascimento), da agricultura (a Assessoria Especial de Gênero, Raça e Etnia) e do Ministério da Justiça, além do Conselho Nacional e das Delegacias Especializadas de Atendimento à Mulher.

Cayres (2015) ainda faz um levantamento acerca do questionamento das concepções dicotômicas de "Estado" e de "movimentos sociais", argumentando que as fronteiras entre eles podem se apresentar de forma difusa e borrada. O mesmo argumento também é levantado por Rangel (2013), que analisa a inserção no Estado por parte de ativistas como "um novo

\footnotetext{
7 Termo cunhado por feministas australianas para designar as feministas que trabalham no Estado (WATSON, 1990)
} 
patamar institucional de intermediação entre Estado e sociedade e de representação nas formas de participação" (RANGEL, 2013, p. 11).

Nesse sentido, Cayres destaca que a maior porosidade do Estado para os movimentos sociais depende do perfil político do governo em atuação, trazendo como grande marco desse relacionamento no Brasil a chegada do Partido dos Trabalhadores (PT) ao executivo de estados, de municípios e da presidência da República. A autora cita a criação de diversas secretarias especiais temáticas, a nomeação de reconhecidos militantes sociais para comando de ministérios e a remodelação da Secretaria Geral da Presidência da República como exemplos de brechas abertas no Estado para a inserção dos atores sociais.

Na mesma direção, Feltran (2006) analisa trajetórias individuais de alguns ativistas que passaram a fazer parte do governo quando o PT chegou à presidência, destacando que a criação de espaços de interlocução entre governo e sociedade estava na agenda política do partido desde o início das contestações populares por democracia, partindo do Estado a demanda para que a sociedade civil se reorganizasse de forma a estabelecer tal interlocução. Desse modo, ganhou força o "tipo de relacionamento institucional entre organizações instituídas e o Estado" (FELTRAN, 2006, p. 402).

Bohn (2010) afirma que governos de partidos políticos ou coalizões progressistas são considerados mais conducentes tanto à implantação de uma agência de políticas públicas para mulheres (APM), quanto ao incremento de sua força institucional no interior da burocracia estatal. Isso porque partidos progressistas usualmente incorporam em sua plataforma programática questões de equidade de gênero, o que os aproxima dos objetivos dos movimentos em prol das mulheres e facilita o processo de legitimação de uma agência de políticas públicas para a mulher.

Pinheiro (2016) também faz coro a essa ideia, enfatizando em seu trabalho a ocorrência da abertura de novos espaços para a interação entre movimento social e Estado no período entre 2003 e 2014, ou seja, enquanto o PT estava na presidência do Brasil. Uma instância bastante relevante nessa temática é a Secretaria de Políticas Públicas para Mulheres (SPM), cuja criação foi uma demanda da ala feminista do Partido dos Trabalhadores e é um exemplo trazido por grande parte da bibliografia que trata desse tema.

Segundo Bohn (2010), a secretaria criada em 2003 expressou uma dinâmica de cooperação entre Estado e movimentos feministas, e não de cooptação, como muitas vertentes dos movimentos sociais temiam. A secretaria, munida de status ministerial, aglutinou desde sua criação grande força institucional no interior do aparelho de estado —isto é, acumulou 
recursos humanos, capacidade técnica, autonomia decisória para assuntos internos e, também, recursos financeiros que lhe permitiam exercer suas atividades de maneira efetiva.

É nítido que a secretaria vem sofrendo significativos retrocessos desde a entrada de Michel Temer, do Partido da Social Democracia Brasileira (PMDB), na presidência da República, em 2016, como a reunião de políticas para minorias em uma única pasta, extinguindo-se então a exclusividade da SPM e retirando-se seu status de ministério, o que desencadeia perdas em todas as instâncias da federação. Portanto, fica explícito o quanto esse tipo de ativismo é influenciado pelo perfil ideológico do governo em questão (pelo partido que está no poder e pelas bandeiras defendidas por este).

É importante enfatizar também que essas medidas criam capacidades estatais para as pautas feministas no Estado, ou seja, deixam marcas e fazem ecoar políticas públicas específicas a esse respeito - a criação da SPM, por exemplo, abriu a demanda para que os estados e municípios criassem pastas específicas para tal política em suas gestões. Essas "marcas" deixadas pela SPM levam à criação de capacidades estatais que possibilitam a inserção de novas personagens em tal realidade.

De acordo com a literatura sobre o tema, as APMs têm maiores chances de êxito em duas situações: primeiro, quando funcionam em administrações que aumentem sua força institucional, o que usualmente ocorre em governos de partidos progressistas; e, segundo, quando a relação entre esta e o movimento de mulheres se desenvolve sob uma dinâmica de cooperação. Esses dois elementos são essenciais à capacidade da APM de introduzir um olhar direcionado às questões de gênero sobre as políticas públicas.

Assim, a importância da abertura do Estado a esse ativismo reforça as tensões existentes dentro do próprio movimento e no relacionamento deste com o Estado, fazendo-se importante repensar a relação entre Estado e sociedade. Baseada em estudos sobre o tema, Mariano (2001), considera que se a entrada no Estado é arriscada no que diz respeito à perda de autonomia do movimento, tal risco é necessário tendo em vista a urgência em se alargar os campos de ação do movimento. Já Rangel afirma que

\footnotetext{
A ideia de autonomia precisa ser repensada no contexto da democratização, uma vez que, quando militantes assumem cargos no governo ou obtêm sucesso em influenciá-lo de fato, a distinção entre Estado e sociedade civil deixa de ser tão nítida. Assim, é possível que atores estatais contribuam para que grupos ou movimentos ganhem capacidades políticas. (RANGEL, 2013, p. 4).
}

Bohn (2010), por sua vez, defende que nem a APM perde sua autonomia decisória nem o movimento de mulheres passa a se confundir com o Estado. Pelo contrário, por um lado, a APM busca continuamente criar redes no interior do Estado que levem à adoção de 
uma perspectiva de gênero no processo decisório e, por outro, o movimento de mulheres exerce pressão sobre o estado para a implementação de políticas públicas que revertam o status desigual das mulheres. Passamos então à exploração de duas trajetórias distintas que podem nos ajudar a refletir sobre os argumentos e expectativas que cercam as ativistas institucionais.

\section{O ATIVISMO INSTITUCIONAL NA PERSPECTIVA DAS FEMINISTAS}

As informações a respeito das trajetórias que aqui nos servem de referência para a discussão das distintas rotas que podem constituir o ativismo institucional foram coletadas a partir de entrevistas realizadas com mulheres que ocupavam cargos na burocracia do estado de Santa Catarina e na Prefeitura de Florianópolis no ano de 2015. A distinção que instigou a comparação das duas trajetórias aqui consideradas diz respeito às rotas inversas $\mathrm{e}$ diferenciadas tomadas por cada uma delas para sua inserção na burocracia estatal. A entrevistada 1 entrou no Estado como uma feminista para atuar num órgão que não é específico para políticas para mulheres, enquanto a entrevistada 2 encontrou-se com o movimento feminista depois de assumir um cargo na burocracia estatal especificadamente responsável pela elaboração de políticas para mulheres. Como veremos, essas diferenças condicionam a forma como essas mulheres atuam e se enxergam como feministas atuantes dentro do Estado.

A entrevistada 1 é formada em Serviço Social e funcionária concursada da Prefeitura de Florianópolis, mas se afastou de sua função para ocupar um cargo comissionado no Governo do Estado relacionado à política de assistência social, que foi conquistado devido à sua inserção na rede de militância partidária. Ela é filiada a um partido de esquerda e engajouse na militância feminista no final dos anos 1990. Seu encontro com as pautas feministas se deu a partir da universidade, durante o curso de graduação em Serviço Social.

A entrevistada 2, também assistente social, passou a dirigir a Coordenadoria Municipal de Políticas Públicas para Mulheres na prefeitura, um órgão vinculado diretamente ao gabinete do prefeito. Ela já havia ocupado, em gestões anteriores, um cargo de gerência em um órgão da administração municipal destinado a políticas para o idoso, e acredita ter sido procurada para assumir a "gerência do setor das mulheres" devido a esse fato (Informação verbal $)^{8}$.

\footnotetext{
${ }^{8}$ Entrevista anônima. Entrevista 2. [ago. 2016]. Entrevistadora: Milena Cristina Belançon. Florianópolis, 2016. 1 arquivo .gpp (30 min.).
} 


\section{ENTRADA, ATUAÇÃO NO ESTADO E AS RELAÇÕES COM OS MOVIMENTOS SOCIAIS}

A entrada da entrevistada 1 na burocracia do Estado se deu a partir de sua conversa com militantes feministas. Sendo esta sua primeira experiência num cargo de confiança, a entrevistada acredita que, por mais que o cargo por ela ocupado seja eminentemente político, a escolha pela sua participação se justifica pela sua competência como técnica e profissional do serviço social (Informação verbal) ${ }^{9}$. Justamente por reconhecer que sua entrada no Estado se deveu também a essa competência técnica, e não apenas à sua inserção em redes de militância política, ela não se enxerga propriamente como uma "representante feminista no Estado". Entretanto, é no desempenho de sua função como assistente social, como uma técnica que trabalha com um conjunto diversificado de políticas, que o seu compromisso com as pautas feministas se expressa. Segundo ela,

O fato de eu ser feminista, de eu ser militante do movimento de mulheres, me coloca um olhar com uma outra perspectiva frente às questões, às demandas e às reivindicações das mulheres e a importância dessas políticas públicas que congregam a secretaria de assistência social do Estado, que é trabalho, habitação, segurança alimentar e assistência social, atinge fortemente a vida das mulheres, principalmente as mulheres que sustentam as famílias. (Informação verbal). ${ }^{10}$

Portanto, sua atuação como feminista se dá a partir do debate com as equipes técnicas sobre a importância de se inserir preocupações de gênero na elaboração de políticas públicas - preocupações estas que reconheçam as diversas discriminações que as mulheres enfrentam na vida em sociedade. Assim, a estratégia da entrevistada 1 é a da disseminação das pautas feministas pelas equipes técnicas da burocracia estatal, num processo que implica convencimento e que ocorre, sobretudo, informalmente, no que podemos chamar de "política dos corredores". Desse modo, podemos perceber aqui o papel das ativistas institucionais na criação das "capacidades estatais" necessárias à promoção de políticas públicas para as mulheres. A ideia de capacidades estatais nos remete às condições das quais dispõem o Estado para a implementação das políticas, o que envolve recursos não apenas financeiros, mas também técnicos e humanos (SOUZA, 2016). A "política dos corredores", tal como aparece nos relatos da entrevistada 1, estimula a formação de uma burocracia estatal não apenas

\footnotetext{
${ }^{9}$ Entrevista anônima. Entrevista 1. [ago. 2016]. Entrevistadora: Milena Cristina Belançon. Florianópolis, 2016.1 arquivo .gpp (40 min.)

${ }^{10}$ Entrevista anônima. Entrevista 1. [ago. 2016]. Entrevistadora: Milena Cristina Belançon. Florianópolis, 2016. 1 arquivo .gpp (40 min.)
} 
preocupada, mas também preparada para introduzir preocupações relacionadas ao gênero na elaboração das suas políticas públicas.

A entrevistada 2, que ocupa um cargo em um órgão específico responsável por políticas para mulheres, considera-se uma representante legítima do movimento feminista, alegando que em todas as decisões tomadas no exercício de seu cargo leva em consideração a trajetória de luta do movimento, a articulação e a legitimidade que conquistou. Segundo ela, "temos que ter esse cuidado porque não nos representamos, nós representamos algo muito maior que são todos os movimentos" (Informação verbal) $)^{11}$.

Já vimos anteriormente que o sucesso desse tipo de ativismo depende do quanto ele mantém ativa sua relação com os movimentos. Como afirma Bohn (2010), os casos mais exitosos de feminismo estatal são aqueles nos quais há uma dinâmica de cooperação entre uma Agência Estatal de Políticas Públicas para Mulheres (APM) e as organizações de mulheres. Nesse sentido, e emprestando os termos utilizados por Young (2006) e Urbinati (2006) para definir uma representação democrática, quanto mais a ativista institucional conecta o Estado aos movimentos sociais, circulando informações, promovendo a prestação de contas e fomentando o estabelecimento de compromissos entre eles, mais seu papel como representante é bem-sucedido. A entrevistada 2 está colocando precisamente nesses termos seus desafios na atuação como ativista institucional. Segundo seus relatos, as demandas feministas enfrentam fortes barreiras para chegar ao Estado e, para vencê-las, é necessário o trabalho das articulações, da ativação das redes e dos pactos, de modo que os projetos elaborados nessas redes possam se transformar não apenas em políticas de governo, mas também em políticas de Estado (Informação verbal) ${ }^{12}$.

O fato de ocupar cargos de direção no Estado já é, segundo as entrevistadas, um ato de resistência. Ambas afirmaram que os homens ocupam maciçamente os mais altos escalões da burocracia estatal, enquanto as mulheres são mais frequentes em postos de segundo escalão. Dessa forma, para além de influir nas políticas públicas, a presença em si de mulheres em cargos de direção já implica uma novidade. Mesmo a entrevistada 2, que opera num órgão voltado para políticas específicas para mulheres, afirmou que "em quase tudo aqui as mulheres são maioria, menos no legislativo e no primeiro escalão do governo, no resto tem mulher pra caramba" (Informação verbal) ${ }^{13}$.

\footnotetext{
${ }^{11}$ Entrevista anônima. Entrevista 2. [ago. 2016]. Entrevistadora: Milena Cristina Belançon. Florianópolis, 2016. 1 arquivo .gpp (30 min.)

${ }^{12}$ Id, 2016.

${ }^{13}$ Id, 2016
} 
Ambas as entrevistadas afirmaram, ainda, que há uma limitação imensa para se efetivar, a partir do Estado, aquilo que é defendido e reivindicado pelos movimentos sociais, devido às restrições orçamentárias e, também, da vontade política dos "superiores" (Informação verbal) $^{14}$. Por isso mesmo, o perfil ideológico do partido que ocupa o governo é um fator essencial no condicionamento da execução das demandas dos movimentos e, também, na própria inserção das feministas na estrutura estatal.

Como já mencionamos anteriormente, a manutenção das conexões com os movimentos sociais é um dos maiores desafios para as ativistas institucionais. Alguns estudos têm mostrado que, de modo geral, os ativistas que atuam por dentro do Estado experimentam imensas pressões e tensões, precisamente pela sua constituição híbrida de Estado e movimento social (ABERS; SERAFIM; TATAGIBA, 2014; CAYRES, 2015). Para a entrevistada 1, é fundamental contar com o apoio e a compreensão dos movimentos sociais diante das limitações que o Estado impõe à sua atuação. Segundo ela, é determinante a troca constante entre o Estado e os movimentos sociais, de modo que a distância entre as demandas destes e as respostas fornecidas por aquele possa ser compreendida (Informação verbal) ${ }^{15}$. Diante de tais cobranças, a manutenção da capacidade de diálogo e de trocas pode evitar o desgaste e, até mesmo, o rompimento dos laços com os movimentos.

Se o desafio experimentado pela entrevistada 1 foi o de evitar o rompimento dos laços com os movimentos, devido às tensão e pressões próprias de seu papel como ativista institucional (a qual tem de responder pelas limitações do Estado em efetivar as demandas que partem dos movimentos), a situação vivida pela entrevistada 2 foi inusitada e nos levou a considerar os impactos advindos da expansão das APMs pelos municípios brasileiros para os feminismos no Brasil. Como já mencionamos, a entrevista 2 encontrou-se com o feminismo após assumir o cargo de direção da Coordenadoria da Mulher na prefeitura. Ela destaca, inclusive, o quanto causou ruído e foi problemática sua nomeação para o cargo, já que não contava com um histórico de engajamento nos feminismos. Segundo ela,

[...] quando eu assumi a coordenadoria [...] eu também não fui muito aceita pelos movimentos de mulheres de Florianópolis por eu não ter vindo de uma militância, não ter uma militância na área da mulher, mas muitas vezes eu fui chamada pra, assim, pra me pôr à prova, pra saber a que eu tinha vindo, e eu consegui, foi muito

\footnotetext{
${ }^{14}$ Entrevistas anônimas. Entrevista 1. [ago. 2016]. Entrevistadora: Milena Cristina Belançon. Florianópolis, 2016. 1 arquivo .gpp (40 min.) e Entrevista 2. [ago. 2016]. Entrevistadora: Milena Cristina Belançon. Florianópolis, 2016. 1 arquivo .gpp (30 min.)

${ }^{15}$ Entrevista anônima. Entrevista 1. [ago. 2016]. Entrevistadora: Milena Cristina Belançon. Florianópolis, 2016. 1 arquivo .gpp (40 min.)
} 
bom esse processo porque eu consegui uma legitimidade muito grande da coordenadoria perante a sociedade. (Informação verbal) ${ }^{16}$.

A aproximação com os movimentos feministas, proporcionada pelo cargo que ocupou na administração estatal, foi fundamental para a entrevistada 2 num momento posterior, em que, diante de uma troca de gestão, ela foi afastada do seu cargo. Nesse contexto, os próprios movimentos reivindicaram sua permanência, como descrito por ela:

O movimento de mulheres, o conselho da mulher, os movimentos da área LGBT se reuniram e ficaram 2013 todo batalhando para que eu voltasse e, em 2014, eu voltei, então. Como no começo eu não tinha uma legitimidade, não me conheciam, então elas ficaram me questionando por um bom tempo, até elas entenderem que eu tinha vindo pra trabalhar e pra tentar ser uma feminista, tanto que uma feminista me disse um dia "Você está se saindo uma excelente feminista", então já tinha toda uma legitimidade. Aí, em 2014, eu volto pra coordenadoria a pedido dos movimentos de mulheres, do conselho da mulher. (Informação verbal) ${ }^{17}$.

A entrevistada 2 nos permite perceber a existência de distintas rotas para se ir ao encontro dos feminismos. Ela se tornou uma aliada do movimento, aderindo às suas pautas e construindo com ele, ao longo do tempo, compromissos e pactos mútuos. Esses laços com o movimento forneceram o capital político que possibilitou que ela permanecesse no cargo na troca de gestão. A entrevistada 2 considera-se um elo importante entre os movimentos sociais e o Estado, afirmando que as mulheres participantes dos movimentos também a consideram, e destacando o fato de ter sido "buscada" novamente pelo movimento durante seu afastamento da coordenadoria. Nas suas palavras,

\begin{abstract}
Hoje, assim, eu sou tranquila em dizer que eu me sinto representando-as. E eu sei que elas me olham assim, então no início elas não me conheciam, porque realmente eu não tinha vindo de uma militância feminista. Isso caiu por terra, então hoje realmente elas sabem que se tiver que bancar uma briga com o governo, eu vou bancar, eu sei como fazer essa briga, eu sei por onde. Que às vezes dá pra avançar, às vezes tem que fazer alguns contornos, fazer outros caminhos, mas que eu vou chegando. E se em algum momento tiver que brigar mesmo, eu também vou brigar, elas sabem [...]. Então, por isso que o nosso setor, a nossa coordenadoria tem legitimidade, e a gente tem uma visibilidade muito boa em Florianópolis, nós acabamos virando referência para o Estado. (Informação verbal) ${ }^{18}$.
\end{abstract}

É crucial notar, assim, a importância da indução federal promovida durante os governos petistas o qual, ao criar a SPM, suscitou a criação de órgãos semelhantes em outras esferas de poder. Esses órgãos não apenas abriram caminhos para a inclusão de feministas na burocracia estatal, mas, como se vê na entrevista 2, propiciaram a aderência ao feminismo de

\footnotetext{
${ }^{16}$ Entrevista anônima. Entrevista 2. [ago. 2016]. Entrevistadora: Milena Cristina Belançon. Florianópolis, 2016. 1 arquivo .gpp (30 min.)

${ }^{17} \mathrm{Id}, 2016$.

${ }^{18} \mathrm{Id}, 2016$.
} 
burocratas femininas com trajetórias políticas não previamente associadas aos movimentos feministas. Ao conquistar uma interlocução com os movimentos sociais e adquirir uma expertise de como fazer políticas públicas para mulheres no interior do Estado, essas burocratas, a exemplo da entrevistada 2, conquistaram um importante capital político junto a partidos políticos de vários matizes, sob o contexto de indução federal para a criação e manutenção de órgãos específicos para mulheres nas administrações municipais e estaduais.

Por isso mesmo, o giro político recente atinge particularmente as políticas ainda fragilmente institucionalizadas, dentre as quais estão as políticas para mulheres. De acordo com a entrevistada 2 ,

O SUS, o SUAS são políticas já definidas, estabelecidas, com normas técnicas, né? E a política da mulher não tem isso, teve um desmonte nacional e isso implicou também aqui embaixo pra nós. Esse desmonte do ministério das mulheres... colocando ele agora dentro de um balaio né, não é mais o ministério direto com a presidência da República. Tudo isso implica aqui no nosso trabalho e também não ter um fundo, não ter recursos específicos, que essa coisa do fundo como tem a saúde e a assistência também é muito importante, nós não temos isso na área da mulher, tanto que a política da mulher acaba ficando subordinada à assistência, porque hoje quem tá financiando é a assistência e não a política da mulher, tudo isso implica. (Informação verbal) ${ }^{19}$.

A partir desse relato, podemos sugerir que a ausência da SPM no âmbito federal diminui os incentivos para que municípios e estados mantenham ou criem órgãos específicos para as mulheres, o que condiciona as possibilidades do ativismo institucional feminista e impacta, de forma mais ampla, as configurações das relações entre movimentos feministas e Estado no Brasil, o que deverá ser tema de vários estudos no próximo período.

\section{CONCLUSÃO}

A partir da revisão bibliográfica e das entrevistas realizadas com feministas institucionais, destacamos alguns pontos nessas considerações finais. É importante sublinhar o desafio, bastante marcado pela bibliografia (e impresso, também, nas falas das entrevistadas), de que as (os) ativistas estatais mantenham uma conexão com os movimentos, com a "rua". Essa conexão se traduziria na "prestação de contas" de quem está dentro do Estado e, também, no acolhimento das demandas "da rua" por ela(e). Desse modo, a ativista institucional pode ser vista como uma mediadora entre o movimento social e o Estado. Por

\footnotetext{
${ }^{19} \mathrm{Id}, 2016$.
} 
isso mesmo, nos casos das secretarias de mulheres, os movimentos têm pautado a discussão sobre quem pode "ser seu representante" no Estado.

Entretanto, para que essa mediação seja possível, pesa muito o perfil ideológico dos governos então atuantes. No que se refere à atuação das feministas e, também, à absorção de suas demandas pelo Estado, é notável que a maioria das políticas para mulheres não é "de Estado", mas sim "de governo", como apontado pelas entrevistadas. Isso faz com que o posicionamento da gestão presente no governo a respeito da questão seja muito relevante. Levando-se em conta a importância que o Partido dos Trabalhadores teve na indução da criação de órgãos específicos para mulheres pelo país, é possível que as mudanças no contexto político impactem as possibilidades que as feministas têm de atuar por dentro do Estado.

Por fim, pode-se notar o quanto o repertório do ativismo estatal questiona concepções dicotômicas de Estado e sociedade, borrando suas fronteiras e exigindo que o próprio conceito de "movimento social" seja repensado, de modo a incorporar indivíduos que carreiem suas pautas para a burocracia estatal.

\section{REFERÊNCIAS}

ABERS, R.; SERAFIM, L.; TATAGIBA, L. Repertórios de interação Estado-sociedade em um Estado heterogêneo: a experiência na era Lula. Dados, Rio de Janeiro v. 57, n. 2, p. 325357, 2014.

ABERS, R.; VON BULLOW, M. Movimentos sociais na teoria e na prática: como estudar o ativismo através da fronteira entre Estado e sociedade? Sociologias, Porto Alegre, v. 13, n. 28, p. 52-84, $\quad$ set./dez. $2011 . \quad$ Disponível $<$ http://www.scielo.br/scielo.php?script=sci_arttext\&pid=S0011-

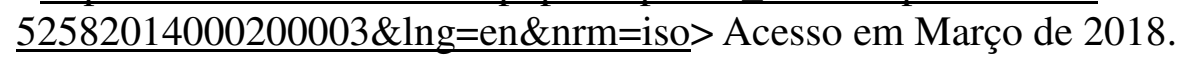

ALVAREZ, S. E. Para além da sociedade civil: reflexões sobre o campo feminista. Cad. Pagu, Campinas, n. 43, p. 13-56, $2014 . \quad$ Disponível em $<$ http://www.scielo.br/scielo.php?script=sci_arttext\&pid=S0104$\underline{83332014000200013 \& \operatorname{lng}=e n \& n r m=i s o}>$ Acesso em Março de 2018.

AVELAR, L. Movimentos, redes e feminismo de Estado: a representação extraparlamentar das mulheres brasileiras. Cadernos ADENAUER, São Paulo, v. 14, p. 71-88, 2013.

Mulher, gênero e política. In: AVELAR, L.; CINTRA, A. O. Sistema político brasileiro: uma introdução. 3. ed. São Paulo: Universidade Estadual Paulista Júlio de Mesquita Filho, 2015. 
BLAY, E. A. Mulheres, movimentos sociais, partidos políticos e Estado. In: COSTA, A. A. A.; SARDENBERG, C. M. B. (Org.). O feminismo do Brasil: reflexões teóricas e perspectivas organizadoras. Salvador: UFBA: Núcleo de Estudos Interdisciplinares sobre a Mulher, 2008.

BOHN, S. R. Feminismo estatal sob a presidência Lula: o caso da Secretaria de Políticas para as Mulheres. Revista Debates, Porto Alegre, v. 4, n. 2, p. 81-106, jul./dez. 2010.

CAYRES, D. C. Ativismo institucional no coração da Secretaria-Geral da Presidência da República: a Secretaria Nacional de Articulação Social no governo Dilma Rousseff (20112014). Tese (Doutorado em Sociologia e Política) - Universidade Federal de Santa Catarina, Florianópolis, 2015.

FELTRAN, G. S. Deslocamentos: trajetórias individuais, relações entre sociedade civil e Estado no Brasil. In: DAGNINO, E.; OLVERA, A.; PANFICHI, A. (Org.). A disputa pela construção democrática na América Latina. Rio de Janeiro: Paz e Terra, 2006.

MARIANO, S. A. Feminismo e Estado: desafiando a Democracia Liberal. Revista Mediações, Londrina, v. 6, n. 2, p. 1-26, jul./dez. 2001.

PINHEIRO, M. B. Feminismo e sua trama de relações: sobre os desafios à transformação do Estado. Trabalho apresentado no 10. Encontro ABCP, Belo Horizonte, 2016.

RANGEL, P. Feminismo de Estado e direitos políticos das mulheres: Argentina e Brasil. Trabalho apresentado no 10. Seminário Internacional "Fazendo Gênero", Florianópolis, 2013.

SOUZA, C. H. L. Capacidades estatais para a promoção de processos participativos: uma análise da forma de organização de conferências nacionais. Tese (Doutorado em Ciência Política) - Universidade de Brasília, Brasília, 2016.

URBINATI, N. Representative Democracy: Principles and Genealogy. Chicago: University of Chicago Press, 2006.

WATSON, S. (Org.). Playing the State: Australian Feminist Interventions. London: Verso, 1990.

YOUNG, I. M. Representação política, identidade e minorias. Lua Nova, São Paulo, n. 67, p. 139-190, 2006

Disponível

em

$<$ http://www.scielo.br/scielo.php?script=sci_arttext\&pid=S0102-

$64452006000200006 \& \operatorname{lng}=\mathrm{en} \& \mathrm{nrm}=\mathrm{iso}>$ Acesso em Março de 2018. 